\title{
Epistemología del riesgo y trama de la vida en tres autores de la modernidad crítica: Jonas, Beck y Giddens
}

\author{
Epistemology of risk and the weave of life in three authors \\ from the critical modernity: Jonas, Beck and Giddens
}

\begin{abstract}
Resumen
Este artículo explora la dimensión epistemológica del riesgo y sus implicaciones en la trama de la vida y el futuro de lo viviente, según tres autores de la modernidad crítica: Hans Jonas, Ulrich Beck y Anthony Giddens. Uno de los elementos que ellos denuncian es la negación del "no-saber" que priva a la sociedad de su capacidad restrictiva frente a las decisiones de riesgo e impide el control social del conocimiento, la ciencia y la técnica. Esta impronta se propone como uno de los rasgos de la colonialidad del saber y de la naturaleza junto a otros como el antropocentrismo, los dualismos enajenantes y el carácter indetenible del desarrollo y el progreso debido a la linealidad temporal que los anima. Finalmente, se sugieren alcances de estos aportes, así como límites y enlaces con el pensamiento decolonial.
\end{abstract}

José Enrique Juncosa ${ }^{1}$

jjuncosa@ups.edu.ec

\section{Palabras claves}

Epistemología, epistemología del riesgo, cultura técnica, control del conocimiento, vida, colonialidad del saber, colonialidad de la naturaleza, pensamiento decolonial.

\begin{abstract}
The article explores the epistemological dimension of risk and its implications in the weave of life and the future of the living according to three authors of the critique of modernity: Hans Jonas, Ulrich Beck and Anthony Giddens. One of the identifying elements is the denial of the "not-knowing" that deprives society of its restrictive capacity in face of risk-based decisions and prevents the social control of knowledge, science and technique. This imprint is proposed as one of the characteristic features of coloniality of knowledge and nature together with others such as anthropocentrism, alienating dualism and the unstoppable feature of development and progress due to a temporal linearity than encourages them. Finally, I proposed a scope, limits and links with decolonial thinking.
\end{abstract}

\section{Keywords}

Epistemology, epistemology of risk, technical culture, knowledge control, life, knowledge coloniality, nature coloniality, decolonial thinking.

Forma sugerida de citar: JUNCOSA, José (2913). "Epistemología del riesgo y trama de la vida en tres autores de la modernidad crítica: Jonas, Beck y Giddens”. En: Universitas, XI (19), julio-diciembre, p. 237-264. Quito: Editorial Abya Yala/Universidad Politécnica Salesiana.

1 Antropólogo, docente y director de la Carrera de Antropología Aplicada y del Centro de Estudios Interculturales (CEI) de la Universidad Politécnica Salesiana. Candidato doctoral en Estudios Culturales Latinoamericanos por la Universidad Andina Simón Bolívar-Quito. 


\section{Introducción}

Esta contribución busca identificar y caracterizar los patrones epistémicos de la moderna colonialidad del saber respecto a la trama de la vida que se expresan en las prácticas de la ciencia y la técnica, y se generalizan y reproducen en la educación superior y la investigación corporativa. Esta investigación exploratoria obedece a la necesidad de repensar críticamente las nociones civilizatorias de desarrollo y progreso inherentes a la ciencia y la técnica desde dos lugares: 1) a partir de los patrones epistémicos que la modernidad colonialidad ha exteriorizado -los saberes otros producidos desde la diferencia colonial- y 2) desde las fisuras y discontinuidades que emergen desde el interior de la misma modernidad colonialidad, tal como aparecen en los aportes del pensamiento crítico y "cosmopolita". 2

La exploración y analítica del riesgo se extiende a tres autores significativos que conforman el segundo bloque de posibilidades: Hans Jonas (1903-1993), Ulrich Beck (1944-) y Anthony Giddens (1938-), y rastrea en ellos las implicaciones epistémicas y políticas de la experiencia del riesgo global respecto a la ciencia y la técnica. A la vez, indaga los patrones de la racionalidad moderna, constituida por una peculiar manera de negar el "no-saber" para eludir enfrentar la incertidumbre.

La idea central de este artículo consiste en que los patrones epistémicos de la ciencia y la técnica -según los autores mencionados- se basan en mecanismos cognitivos y de toma de decisiones incapaces de afrontar el riesgo global porque niegan la imposibilidad de dimensionar las consecuencias futuras sobre la vida y despojan a esta imposibilidad de saber de su potencial restrictivo. Si bien para los autores revisados el riesgo constituye un lugar privilegiado que evidencia la necesidad de trascender la modernidad como totalidad diferenciada (Giddens, 1990; Beck, 2008), atada a una racionalidad condicionada al sometimiento de la naturaleza y la aniquilación de la vida, el presente análisis

2 Entendemos el concepto de "modernidad cosmopolita" como el proyecto político que busca superar la segunda modernidad atravesada por la sociedad industrial, en el sentido que le atribuye Beck (2008), como el momento contemporáneo, diferente y cosmopolita que emerge de la conciencia del riesgo global y de sus posibilidades de ruptura. (Véase el "Manifiesto cosmopolita" que precede el libro de Beck $L a$ sociedad del riesgo mundial [2008]). 
asume el riesgo como señal de una crisis civilizatoria más profunda, tal como propone Lander:

El patrón civilizatorio que ha intentado universalizarse durante estos últimos 500 años está acercándose a hacer que la vida en el planeta Tierra ya no sea posible. Cuando hablamos de cambio climático o de las condiciones del agua, de la destrucción de la biodiversidad, no nos encontramos apenas ante una crisis ambiental sino ante una profunda crisis civilizatoria. Por tanto, estamos también ante el abordaje de un cuestionamiento a este patrón civilizatorio (Lander, 2010: 27).

Desde las connotaciones epistémicas del riesgo es posible comprender mejor la transformación histórica más importante de las prácticas de conocimiento y producción tecnológica también señalada por Lander (1994): la emergencia de una nueva temporalidad basada en la incertidumbre del futuro de lo viviente debido a causas antropogénicas, un horizonte que relativiza el alcance de las soluciones no solo por inadecuadas, sino también porque pueden resultar irrelevantes, ${ }^{3}$ a tal punto que la existencia de las formas de vida en el planeta y la sobrevivencia de quienes piensan y se autoconciben como sujetos éticos y políticos no solo no está garantizada, sino y sobre todo, se encuentra seriamente amenazada.

\section{No-saber y evaluación del riesgo en el contexto de la "ética crí- tica" de Hans Jonas}

Jonas, a lo largo de su obra (1984, 1995, 1997, 2000 y 2005), profundiza al menos tres intuiciones que sustentan una de las críticas más profundas a la ciencia y a la capacidad de acción técnica sobre lo viviente. Estas son: 1) la noción de naturaleza como totalidad de lo viviente, dotada de intencionalidad y finali-

3 Otras transformaciones evidenciadas por el mismo autor son las siguientes: 1) progresiva sustitución del modelo académico liberal y sus formas de producción, validación, difusión y control de los conocimientos por el modelo corporativo; 2) inclusión del conocimiento, junto a sus aplicaciones, en el grupo de bienes "garantizables" por la legislación internacional de derechos de autor y licencias; 3) la relación inédita del conocimiento y de las innovaciones tecnológicas con la participación y la democracia, en términos de control social y evaluación de los impactos y consecuencias. 
dad porque el fin común de todo viviente es asegurar(se) la vida; la naturaleza no obedece solo a leyes, también está habitada por valores y motivaciones; 2 ) la comprensión de lo humano como organismo viviente y el reconocimiento de lo orgánico como constitutivo de la subjetividad humana, llamada a responder y asegurar no solo su propia sobrevivencia, sino la de todo lo viviente; 3) concebir la subjetividad como organismo viviente implica, a su vez, la superación de todo dualismo (noúmeno-fenómeno, mente-cuerpo, sociedad-naturaleza, reino de la necesidad-reino de la libertad, etc.) porque enajena y escinde del ser. ${ }^{4}$

Estas intuiciones de fondo le han llevado a formular su aporte más conocido en el campo de la ética: El principio de responsabilidad (1995[1984]), enfocado en la necesidad de controlar el poder de la acción humana sobre lo viviente (puedo, entonces debo), en contraposición a la ética kantiana del deber que abstrae el mundo humano de la vida (debo, entones puedo) (Giner, 2005: 37). La primera consecuencia epistémica de esta responsabilidad por la vida es otorgar peso y significado al ser de la naturaleza (hacerse cargo de la vida) antes que a la naturaleza del ser (comprender lo que la naturaleza es, sus leyes) (Giner, 2005: 15-16). Aunque Jonas, respecto a Giddens o Beck, no es tan explícito ni extenso a la hora de considerar el riesgo, su aporte contribuye a evidenciar los límites del conocimiento y la acción humana respecto al destino de lo viviente, de manera que valoriza el "no poder saber aún", otorgándole no solo capacidad de restricción legítima respecto a las consecuencias de la ciencia y la técnica; también le otorga a este no-saber el carácter de una condición existencial.

Para entender su aporte, es necesario partir de su cuestionamiento a la "ética tradicional" (Jonas, 1984: 4-5 en Lander, 1994: 137-138) a la luz de la "ética crítica", en paralelo al camino recorrido por la "teoría crítica" de Horkheimer (2003) respecto a la "teoría tradicional".

La ética crítica de Jonas evidencia y denuncia los siguientes elementos de la ética tradicional que alimentan relaciones de dominio respecto a lo viviente: 1) neutralidad ética de la actividad humana respecto a la naturaleza; 2) carácter antropocéntrico de la ética tradicional que desconoce las relaciones con la naturaleza y lo viviente; 3) Concepción de la naturaleza como realidad dada,

4 Una introducción general al pensamiento de Jonas la ofrece Illana Giner Comín, en su "Introducción” a la edición española de Poder e impotencia de la subjetividad (Jonas, 2005: 13-70). 
incompleta o imperfecta sin la intervención humana y, por lo tanto, objeto necesario de su acción. Así, la visión tecnológica se instaura desde una visión optimista de sus propias posibilidades sobre un trasfondo pesimista respecto a la naturaleza, considerada como algo dado sin valor y disponible a cualquier apuesta de mejoría (Lander, 1994: 138, 143).

Las transformaciones sugeridas por la ética crítica de Jonas cuestionan el primado del bien humano (antropocentrismo) al mismo tiempo que identifica la naturaleza como la totalidad de la biosfera del planeta y polo obligado de la acción ética. Estas transformaciones, en las que se expresan de diversa manera la conciencia del riesgo, son las siguientes: 1) incorporación relacional de un nuevo referente ético: el referente de la naturaleza pues, en efecto, el objeto del cuidado es "la entera biosfera del planeta [...], ya que tenemos poder sobre ella" (Jonas, 1995: 84 en Giner, 2005: 26); 2) visión de una naturaleza completa en sí misma, que no requiere de la acción humana para culminarse o perfeccionarse, tal como prescribe la mitología creacionista; 3 ) superación y relativización de la esfera próxima e inmediata de la acción humana (en lo temporal y lo espacial); 4) superación del sentido de neutralidad ética de las acciones tecnológicas a favor de la capacidad de anticipar y condicionar el futuro y de la necesidad de considerar los riesgos ante la posible irreversibilidad de ciertos efectos; 5) inclusión del "riesgo" probable aunque no demostrable -e imposible de sustentar científicamente- como factor legítimo de "restricción responsable" pues no existe en el presente un saber disponible para comprender o anticipar los riesgos (Lander, 1994: 139ss., a partir de Jonas, 1995).

En otros lugares, Jonas hace del riesgo un atributo ontológico de los seres más dotados de individualidad y libertad, cuya condición está atravesada, por lo mismo, de una mayor cuota de riesgo, pues han incrementado también sus necesidades. ${ }^{5}$

En cuanto al no-saber, Jonas lo asume, en ciertas circunstancias, como derecho, en atención a la manera cómo se concibe la naturaleza y la subjetividad.

5 Giner (2005: 45), refiriéndose a este aspecto formulado por Jonas en El principio vida (2000: 149-160), dice lo siguiente: "lo orgánico se caracteriza por una dialéctica incancelable entre libertad y necesidad: la vida se plantea como una lucha incesante por la supervivencia en cuyo decurso los organismos más evolucionados ganan cuotas de libertad e individualidad, pero al precio de un aumento proporcional de sus necesidades y del riesgo que implica la propia supervivencia". 
En relación a la naturaleza, dotada de una dignidad y autonomía que es necesario respetar (Jonas, 1995: 35), propone una actitud de respeto y humildad pues ella también exige ser, más que comprendida e indagada, escuchada (véase Giner, 2005: 34ss.). La indagación exhaustiva de sus leyes, más allá de la necesidad de garantizar la vida, puede constituir un abuso contra su dignidad. En el campo de la subjetividad humana, Jonas plantea una situación (la clonación de seres humanos) en la que el no-saber se constituye en un derecho que se erige en argumento para cuestionar éticamente la clonación porque atenta contra el imperativo de todo individuo para lograr comprenderse y encontrarse a sí mismo. La duplicación atenta contra estos imperativos: "un hombre clonado de un individuo existente ha visto vulnerado sus derechos existenciales fundamentales, concretamente el derecho a no-saber de sí mismo, sino encontrarse, abrirse su propio camino, probar sus posibilidades y sorprenderse a sí mismo" (Jonas, 1997: 197).

El pensamiento de Jonas también deslegitima otras nociones que obnubilan la conciencia del riesgo. La principal de ellas es la noción de progreso, un elemento que "toca el fondo del asunto" como ningún otro (1997: 21-22), pues es asumido como "condición objetiva" engañosamente autoevidente, que funciona como "premisa de que puede haber un progreso ilimitado, porque siempre hay algo nuevo y mejor que encontrar" (Jonas, 1997: 21). Su fuerza radica en la visión teórica subyacente del orden mismo de las cosas "y del conocimiento de ellas, según la cual éstas no ponen límite alguno al descubrimiento e invención, más bien abren en cualquier punto a partir de ellas un nuevo acceso a lo aún por conocer y por hacer" (Jonas, 1997: 21).

Así, el progreso es el "resorte más íntimo" de la ciencia y la técnica pues el movimiento de incondicionada apertura de la ciencia de ir, respecto a la naturaleza, siempre más allá de las fronteras del conocimiento se traduce, en la técnica, en otro que atribuye a la naturaleza el carácter de inagotable. Ese horizonte alimenta un sentido de la naturaleza atravesada por la "infinitud virtual" (Jonas, 1997: 22), perpetuamente disponible e inagotable, y sujeta a un progreso indefinido que bloquea la anticipación del riesgo porque, simplemente, estorba la dinámica "automotiva" de la ciencia y la técnica.

La apuesta epistémica de Jonas prioriza la "heurística del miedo" o los mecanismos de la "profecía del desastre" (Lander, ídem: 142 ss.) que sustituyen 
las promesas de futuro de gloria inherentes a la ciencia. La "prognosis del desastre" es mucho más adecuada que la "prognosis de gloria" por tres razones: 1) porque los argumentos a favor de la tecnología resultarán mejor fundados racionalmente que las predicciones de sus consecuencias futuras difícilmente defendibles; 2) porque la heurística del miedo será necesaria en tanto no seamos capaces de reinstaurar una metafísica que cierre la brecha entre "ser" y "deber ser" y logre adecuar la tecnología a una concepción de la responsabilidad del hombre no solo para consigo mismo, sino para con la plenitud de la vida y su posteridad; el saber filosófico debe desarticular la autonomización compulsiva y automotiva de la ciencia y la técnica que tiende a instaurar una lógica irreversible que se "sobrepone a los deseos y planes de los iniciadores" (Jonas, 1884: 31 en Lander, 1994: 144-145); y 3) porque la acción tecnológica puede provocar cambios colosales y muchas veces irreversibles que superan los mecanismos del "jugar seguro" propios de la evolución, la cual, en cambio, produce pequeñas transformaciones que se validan poco a poco.

Los desafíos epistemológicos de la ética del futuro se relacionan con cada uno de los tres argumentos expuestos. Respecto a los dos primeros (insuficiencia del saber y prognosis del miedo), el principal desafío de la ética del futuro es instalar un saber filosófico que no dependa del grado de certidumbre factual proporcionado por la ciencia (Jonas, 1884: 29 en Lander, 1994: 143), saber que privilegia la imaginación anticipatoria y su capacidad de enfrentarse a un mal aún no experimentado, sin analogías en el pasado y el presente. El segundo deber se relaciona con el cultivo de una disposición emocional capaz de tomar en cuenta amenazas no inmediatas y distantes en el futuro, pero de tal forma que no alimenten la curiosidad o induzcan al pesimismo inmovilizante.

La ética de la responsabilidad conlleva también desafíos políticos que apuntan a restablecer el control sobre un poder que se ha ido de las manos. El lugar para ejercer el poder sobre el poder de la técnica es la sociedad y no el mercado:

La economía "libre" de las sociedades industriales occidentales está en la propia fuente de la dinámica que impele al peligro moral [...]. Una cosa está clara: solo un máximo de disciplina social políticamente impuesta puede asegurar la subordinación de las ventajas del presente a las exigencias a largo plazo del futuro (Jonas, 1984: 142 en Lander, 1994: 145). 
Sin embargo, según Jonas, no son la democracia ni un Gobierno representativo los llamados a ejercer esta responsabilidad total por su afincamiento en los intereses presentes y por la imposibilidad de representar el futuro ("lo que no ha nacido no tiene poder"), sino una élite ilustrada, con poder para el ejercicio del futuro de tal manera que "la responsabilidad ética quedaría desplazada del individuo al cuerpo social en su conjunto" (Lander, 1994: 147). El pesimismo de Jonas respecto a la capacidad de la democracia y de la representación social es uno de los aspectos más polémicos de su obra. No obstante, refleja una conciencia lúcida del alcance de los riesgos potenciales de la ciencia y la técnica y la gravedad que implican: "la política pública nunca ha tenido que tratar con asuntos de tal inclusividad y tales lapsos de anticipación. De hecho, el cambio en la naturaleza de la acción humana cambia la naturaleza misma de la política" (Jonas, 1984: 9 en Lander, 1994: 144).

La apuesta de Jonas tiene enlaces significativos con Beck porque ambos atribuyen valor a la incertidumbre y la probabilidad que nacen de la insuficiencia de nuestro conocimiento predictivo y de la brecha insalvable entre la limitada capacidad de extrapolar las posibles consecuencias de las intervenciones tecnológicas y el potencial cada vez mayor de la tecnología:

La requerida extrapolación exige un grado de ciencia exponencialmente mayor que la que está presente en la tecnología de la cual se extrapola. Y como esta representa en cada caso el vértice de la ciencia disponible, el conocimiento requerido estará necesariamente "todavía no" disponible (Jonas, 1984: 29 en Lander, 1994: 141).

Al mismo tiempo, aunque el enlace con Giddens es más tenue, proporciona argumentos que contribuyen a desmontar la fiabilidad obligada respecto a los sistemas expertos, un tema central en este último autor.

\section{Epistemología y política del riesgo según Ulrich Beck}

Beck, en su obra La sociedad del riesgo mundial (2008, véase también Beck, 1999), propone una ontología y epistemología (además de un propuesta ética y política) del riesgo a partir de algunas experiencias y acontecimientos 
catastróficos constitutivos de la segunda modernidad, cuya experiencia ha erosionado el sentimiento de seguridad que fundamenta las relaciones sociales y económicas y ha producido importantes restricciones en la libertad individual, considerada, esta última, una de las conquistas clave de la modernidad. Algunas de esas experiencias son las siguientes: la anticipación de ataques terroristas, la posibilidad de excluir genes de riesgo en la configuración de los futuros individuos, la conciencia de las consecuencias fatales del cambio climático, las crisis financieras, entre otras (Beck, 2008: 15ss.). Para Beck, la experiencia del riesgo más que una situación es una calidad históricamente nueva, una nota diferencial de la sociedad industrial moderna causada, antes que por sus sistemas productivos, por la racionalidad de la modernidad. Esta nueva calidad confronta la sociedad moderna consigo misma, colocándola en otro estadio (Beck, 1996: 203-208) que incluye un escenario de contramodernidad y la posibilidad de su propia autodisolución.

De la "semántica del riesgo" basada en la probabilidad que percibe el riesgo en términos de oportunidad y peligro, ${ }^{6}$ es decir, como movilizador del pensamiento y la acción (arriesgarse a cruzar el océano para descubrir nuevas tierras), emerge una semántica según la cual el riesgo ya no es sinónimo de probabilidad movilizadora sino de amenaza real para la vida en la que el cálculo de las consecuencias resulta esencial para la sobrevivencia del género humano: "el riesgo adquiere un nuevo carácter porque parte de que las condiciones de su cálculo y procesamiento institucional fallan" (Beck, 2008: 23). Este pasaje es la clave de comprensión del nuevo clima moral y político de la segunda modernidad -o de la sociedad del riesgo mundial- que ha transformado no solo los espacios de opinión pública, sino también la percepción de los roles de la ciencia y de la técnica, de la responsabilidad de los Estados y de las agencias sociales. Si bien las derivaciones éticas y políticas constituyen el objetivo principal del libro de Beck, nos centraremos en los factores ontológicos en torno al riesgo (en qué consiste, cuáles son sus rasgos), en los epistemológicos y metodológicos (qué

6 “Cuando Descartes enuncia el 'yo pienso' como el fundamento de todo y de todos, hace aparecer en escena, además del riesgo, un yo que actúa contra los dioses y contra un futuro predestinado, una postura que bien puede calificarse hegelianamente de 'heroica' [...]. Todo lo perteneciente a la experiencia del riesgo [...], todo culmina en la frase (naturalmente irónica y que hay que entender como un juego de palabras): 'Arriesgo' ergo sum. Me arriesgo, luego existo; sufro, luego existo” (Beck, 2008: 21). 
maneras de conocer desautoriza o solicita) y en las formas de escenificación del riesgo.

\section{Ontología y sociología del riesgo}

Beck (2008: 83-84) menciona los siguientes rasgos constitutivos del riesgo: 1) Deslocalización: el riesgo es omnipresente e implica una deslocalización espacial que trasciende las fronteras nacionales al mismo tiempo que una deslocalización temporal que trasciende el presente y un futuro previsibles; y una deslocalización social cuyos efectos de largo plazo no se pueden restringir y circunscribir a poblaciones determinadas. 2) Incalculabilidad: pues las consecuencias son indeterminables y producidas por los disensos normativos y el no-saber de la ciencia. 3) No-compensabilidad: pues los daños son irreparables.

A esta ontología le sigue la dimensión sociológica, la más importante, según la cual el carácter clasista es la "esencia del riesgo" (Beck, 2008: 195) expresada en la interdependencia entre riesgo y desigualdad, riesgo y dominio. El riesgo es, sobre todo, una categoría política directamente aparejada a las desigualdades y asimetrías sociales entre quienes tienen el poder de definir y tomar decisiones mediante las cuales algunos (los poderosos y los expertos) desencadenan riesgos que terminan constituyéndose en peligros para los más débiles:

El riesgo presupone una decisión, o sea, un decidente, y genera una asimetría radical entre aquellos que provocan y definen los riesgos y se aprovechan de ellos, y aquellos a los que les toca sufrir en su propia carne, incluso pagando con su propia vida, las "consecuencias indirectas no vistas" de unas decisiones en las que no han participado (Beck, 2008: 196).

No obstante, la vinculación entre riesgo y desigualdad es relativa pues "cuanto mayor el peligro, menor la posibilidad de distribuirlo desigualmente" (Beck, 2008: 250).

El segundo aspecto de la sociología del riesgo consiste en su capacidad de funcionar como "aglutinante para la diversidad" (Beck, 2008: 256) y productor de pertenencias identitarias basadas en comunidades de riesgo articuladas según dicotomías conflictivas. Ello se ilustra, por ejemplo, en el conflicto entre 
fumadores y fumadores pasivos. El riesgo produce un "nosotros" desde el cual actuar y representar, definir e intentar controlar los riesgos. Por tanto, la sociología es inherente a la ontología del riesgo, pues se trata de quién los define y los circunscribe: "no existe el riesgo, sino más bien dos visiones excluyentes y más o menos irreconciliables del mismo" (Beck, 2008: 256).

La ontología y sociología del riesgo produce quiebres respecto a la visión del mundo propia de la primera modernidad. Así, merced a su borrosidad el riesgo se reviste de naturaleza cosmopolita pues las causas y soluciones de los problemas locales se ubican en otros lugares; se borran, así, las distinciones interior/exterior y la dinámica de los problemas resultan no lineales y discontinuas en el espacio y el tiempo y, por lo tanto, imprevisibles, difícilmente compresibles y menos aún, gestionables. El riesgo así producido por la segunda modernidad cuestiona los fundamentos epistémicos de los saberes lineales propios de la sociedad industrial.

\section{Implicaciones epistémicas del riesgo}

El peligro emerge no tanto del tamaño de la amenaza como de una actitud epistémica propia de las instancias que toman decisiones. La percepción del riesgo implica "anticipar lo que no puede anticiparse" y, por tanto, obrar en la perspectiva del no-saber en el estricto sentido de que "no sabemos que no sabemos". Precisamente, de esta actitud que propicia y detona la acción "brotan los peligros que amenazan a la humanidad" (Beck, 2008: 77). ${ }^{7}$

Beck (2008: 79) rescata tres posibles actitudes ético-cognitivas frente al riesgo: 1) la negación (propia de la modernidad), 2) la apatía (propia del nihilismo de la posmodernidad) y 3) la transformación (propia del momento cosmopolita de la sociedad del riesgo mundial). La negación adquiere una expresión particular en el uso de la duda por parte de los estados según la lógica del laisser-faire ("en la duda, por la duda") que resulta inviable y suicida frente

7 'No se trata, pues, del tradicional 'aún no-saber', sino del no-saber no sabido o inadvertido. Y es esta clase de poder no-saber la que tiene que considerarse 'causa' de la amenaza a la humanidad” (Beck, 2008: 175). 
al riesgo. La sociedad industrial niega a tal punto el riesgo que "fabrica sus consecuencias negativas y autoamenazas sistemáticamente pero no las tematiza públicamente en forma de conflictos políticos" (Beck, 2008: 157). Ante ello, Beck (2008: 148) plantea el principio opuesto: "en la duda, contra la duda", lo cual implica sustituir la metodología de la incertidumbre por la metodología de la inseguridad.

A renglón seguido, Beck identifica dos formas de conocimiento diferentes y mutuamente excluyentes según el tipo de casualidad: la lineal (blanda y simple) y la no lineal (dura y reflexiva). La primera produce un tipo de modelización de la incertidumbre que busca su contención eficiente "a fin de hacerla asimilable socialmente" (Beck, 2008: 83). La modalidad lineal informa y modela el patrón epistémico de la ciencia moderna (Beck, 2008: 81-82) -así como los criterios de gestión del riesgo a ella asociados-según la lógica de la "Campana de Gaus" que atribuye significatividad a las distribuciones normales, a las regularidades $\mathrm{y}$ frecuencias previsibles, claramente anticipables y, por tanto, manejables; al mismo tiempo que desecha o marginaliza en los bordes las anomalías por considerarlas irrelevantes. Ante ello, postula la modalidad de pensamiento dura y reflexiva según la cual las anomalías, los saltos abruptos y las discontinuidades, son el correlato obligado del riesgo. La ciencia - las ciencias naturales - y el conocimiento en general deben operar un giro a favor de la modalidad no lineal: "la atención tiene que dirigirse principalmente a las excepciones, que solo confirman la regla aparentemente" (2008: 82). Esta distinción denuncia la inadecuación y desfase del paradigma lineal de la ciencia respecto a los riesgos globales, pues "vivimos en un mundo impulsado principalmente por saltos causales y por eso los instrumentos diseñados para procesos casuales yerran el problema" (Mandelbrot y Taleb, 2006: 2 en Beck, 2008: 83).

Las condiciones de reproducción del riesgo están aparejadas a las actitudes epistemológicas y de gestión, pues cuantas más decisiones se toman desde tal racionalidad más riesgos se producen. Así, el no-saber genera, a su vez, un ciclo ontológico de reproducción del riesgo según el cual "cuanto más decididamente se niega la sociedad del riesgo, más realidad se hace esta [y] quien niega el cambio climático lo acelera" (Beck, 2008: 77, 131). Asimismo, la dinámica de reproducción del riesgo es directamente proporcional a los intentos de control 
y manejo producidos desde la racionalidad lineal de las decisiones científicotécnicas (Beck, 2008: 159) garantizando el incremento exponencial del riesgo.

Por tanto, la "sociedad del riesgo mundial" introduce dos nuevas transformaciones que enlazan el conocimiento y la política: en primer lugar, el progreso técnico y sus consecuencias se convierten en bienes colectivos; y en segundo lugar, estos bienes deben insertarse en formas adecuadas de toma de decisiones democráticas.

La sociedad del riesgo mundial propone actitudes, metodologías y acentos nuevos en las prácticas del conocimiento algunas de las cuales resumimos a continuación. En primer lugar, sugiere el primado de un saber autocrítico, no basado tanto en la ciencia y la experiencia sino en la imaginación, la sospecha, la ficción y el temor; ${ }^{8}$ en segundo lugar, Beck propone valorar el no-saber para evidenciar la locura que supone "tomar decisiones sobre un futuro incierto en medio del poder no-saber” (Beck, 2008: 175); en tercer lugar, y en relación a las ciencias sociales, la urgencia de comprender al otro es sustituida por el derecho del otro a ser comprendido (Beck, 2008: 257). La base del "comprender cosmopolita" y la subsecuente "hermenéutica cosmopolita" consiste, pues, en sustituir el derecho de comprender por el de ser comprendido y escuchado.

\section{Política y escenificación del riesgo}

En un escenario del no-saber, las percepciones resultan más importantes que el conocimiento. Es así que, en el debate del rol de las ciencias de cara al riesgo, Beck (2008: 124ss.) introduce una discusión importante respecto a dos maneras insatisfactorias de escenificar y visibilizar los riesgos naturales: la primera de ellas se refiere a las ciencias naturales y la conformación de la conciencia ecológica más allá de las concepciones de la naturaleza como un “en sí". La conciencia ecológica se constituye sobre una visión altamente cientifizada de

8 "El principio de la previsión exige un ejercicio activo de la duda en el sentido en que Descartes la canonizó en sus Meditaciones. Antes de cualquier acción tengo que preguntarme no solo qué tengo que saber o controlar sino también qué no sé, qué temo o supongo. Tengo que plantearme precavidamente la posibilidad más mala. Esta es la consecuencia de que un daimon infinitamente mentiroso y malvado pueda haberse deslizado en una empresa aparentemente inocente" (Ewald, 2002: 285 en Beck, 2008: 169). 
la naturaleza y, por tanto, atravesada también por la posibilidad nada deseable de abstraer los riesgos e invisibilizarlos adecuadamente. Al ser la visibilización de los riesgos un aspecto clave para la sociedad cosmopolita, la modelización científica ofrece menos posibilidades como las que ofrece la segunda manera escenificar y visibilizar los riesgos naturales: la visibilización "cultural". Esta última implica reconocer que los peligros no son nada en sí, sino en tanto resultado de las escenificaciones sociales (una dramaturgia pública) que "con la utilización estratégica de material científico, se definen, velan, dramatizan ante la opinión pública" (Beck, 2008: 125). Esta segunda posibilidad, también insatisfactoria, reduce a mera representación cultural la materialidad real de los riesgos.

Para superar las falencias de ambos lugares (la abstracción del uno y la irrealidad del otro), Beck propone la combinación entre la mirada realista y la constructivista. La realista no pierde de vista la irreversibilidad del deterioro y la destrucción; en tanto que la mirada constructivista no descuida la necesidad de convertir este escenario en una oportunidad de acción política. Por último, la noción de riesgo tal como nos la presenta Beck requiere una nueva agenda teórica que

Primero, desacople sociedad de Estado nacional; segundo, niegue la presunción de que la sociedad pueda ser controlada por nadie; tercero, ya no conciba la modernidad como un proceso de diferenciación funcional que se autoperpetúa sino como un proceso que alberga el fundamento de su autodisolución, autoamenaza y autotransformación [...] y, cuarto, ponga su máxima atención, por lo que se refiere a los riesgos globales, en el desacoplamiento del nosotros de los decidientes del nosotros-consecuencia-indirecta (Beck, 2008: 223).

\section{Riesgo y fiabilidad en Anthony Giddens}

Según Giddens (1996: 37), la "modernidad superior" -el estado presente de la modernidad-se caracteriza por una inédita conciencia de riesgos globales también inéditos tales como la posibilidad de una guerra nuclear, la catástrofe ecológica y el colapso financiero. Por lo tanto, la modernidad superior no es tanto una sociedad en la que el riesgo se hace presente, la modernidad, más 
bien, "es una cultura del riesgo" (Giddens, 1996: 36), pues vive y se articula a su alrededor, especialmente, sus dispositivos e institucionalidades de conocimiento. ${ }^{9}$ Para el análisis de su aporte, nos basamos mayormente en la obra Consecuencias de la modernidad (2008), en la cual considera la conciencia del riesgo y la fiabilidad desde las condiciones de reproducción de las dimensiones institucionales que hacen posible la modernidad; ambas, la conciencia del riesgo y la fiabilidad, modelan la racionalidad moderna y los mecanismos institucionalizados de conocimiento y toma de decisiones frente a la vida.

Giddens (2008: 28-59) identifica tres condiciones o fuentes de dinamismo de la modernidad mediante las cuales se ha expandido y reproducido a sí misma y lograr transcender órdenes anteriores. Tales condiciones, que constituyen la lógica profunda de las dimensiones institucionales de la modernidad (vigilancia, capitalismo, poder militar e industrialización) son: 1) la desarticulación y distanciamiento del espacio-tiempo, 2) el desanclaje y 3) la reflexividad.

La primera condición, la desarticulación del tiempo y del espacio, produce la organización racionalizada que vincula como nunca antes lo local con lo global; e introduce la visión radical de la historia como medio de apropiación sistemática del pasado y configuración del futuro. Al mismo tiempo, permite apropiarse y controlar lugares y tiempos locales a partir de entidades vacías y estandarizadas (expresados en un mapa y un calendario universal).

La segunda condición, el desanclaje, hace posible “'despegar' las relaciones sociales de sus contextos locales de interacción y reestructuración en indefinidos intervalos espacio-temporales" (Giddens, 2008: 32). Se trata de la cara inversa de la contextualización que reduce las particularidades de los grupos sociales a momentos o episodios de esquemas históricos o sistémicos más amplios, como si se tratase de fases de diferenciación progresiva, diversificación o de especialización funcional. El desanclaje corta las conexiones existentes

9 "La modernidad es una cultura del riesgo. Esto no significa que la vida social moderna es de suyo más arriesgada que la de sociedades precedentes; para mucha gente, desde luego, no es el caso. Más bien, el concepto de riesgo deviene fundamental para el modo en que los actores sin especialización y los especialistas técnicos organizan el mundo social. Bajo las condiciones de la modernidad, el futuro es esbozado en el presente por medio de la organización reflexiva de los ambientes de conocimiento" (Giddens, 1996: 36). 
Entre la actividad social y su "anclaje" en las particularidades de los contextos de presencia. Las instituciones 'desvinculadas' extienden enormemente el ámbito de distanciamiento entre tiempo-espacio. Este fenómeno sirve para abrir un abanico de posibilidades de cambio al liberar de las restricciones impuestas por hábitos y prácticas locales (Giddens, 2008: 31).

A su vez, el desanclaje es seguido por el reanclaje o "reapropiación o disposición de las relaciones sociales desvinculadas, para relacionarlas con [...] las condiciones locales de tiempo y lugar" (Giddens, 2008: 81).

La tercera condición es la reflexividad, que si bien es un rasgo de toda acción humana (toda acción supone la relación consciente entre medios y fines), en la modernidad se reviste de un carácter distintivo que atañe a la manera cómo se sanciona la práctica social no ya desde la integración o reinterpretación de la tradición sino desde el saber experto y su difusión sobre la vida social. En la modernidad, la reflexividad es "introducida en la base del sistema de reproducción de tal manera que pensamiento y acción son constantemente refractados uno sobre el otro" (Giddens, 2008: 46). Así, el conocimiento social se vuelve constituyente de la vida social (la produce, de alguna manera) porque se imbrica en las prácticas e incide en la vida cotidiana de la gente. ${ }^{10}$

El desanclaje, la segunda condición de reproducción de la modernidad, se conecta de manera particular con la cognición del riesgo y de la fiabilidad. Debe su dinamismo a la fiabilidad en sistemas abstractos de dos tipos: las "señales simbólicas y los sistemas expertos" (Giddens, 2008: 32). Se entiende por señales simbólicas a los medios de intercambio que pueden ser pasados de unos a otros sin tomar en cuenta "las características de los individuos o grupos que los manejan en un particular coyuntura" (Giddens, 2008: 33). Los sistemas expertos, en cambio, son "sistemas de logros técnicos o de experiencia profesional que organizan grandes áreas del entorno material y social en el que vivimos" (Giddens, 2008: 37).

Ambos sistemas - las señales simbólicas y los sistemas expertos- suponen un tipo de fiabilidad basada en compromisos anónimos (Giddens, 2008: 81) y

10 Para entender esta dimensión pueden servir los siguientes ejemplos: la difusión de estadísticas sobre el divorcio puede influir las decisiones de las posibles parejas en mayor medida que los principios o la adhesión a una u otra tradición ética o religiosa. Lo mismo vale para el innegable impacto de conceptos tales como capital, interés o inversión en la conducta económica cotidiana de los legos. 
en capacidades abstractas que requieren de compromisos de presencia caracterizados por la formalidad y la fugacidad uno de cuyos ejemplos es el dinero, en cuyo caso la fiabilidad depende no de la persona que lo posee sino de las emisiones gubernamentales (Giddens, 2008: 36-37). La fiabilidad es una manera de enfrentar el riesgo y

Expresa el sentimiento que existe entre nuestra noción de ser y el ser en sí mismo, una definitiva conexión y unidad, una cierta consistencia en nuestra concepción sobre ello, una seguridad y la ausencia de resistencia en la entrega del ego a su concepto, que si bien puede descansar sobre razones particulares, no llega a explicarla (Simmel, 1978 en Giddens, 2008: 36-37).

Antes que una "mera comprensión cognitiva", la fiabilidad expresa un compromiso con algo a partir de resultados probables (Giddens, 2008: 37), de tal manera que obedecemos los semáforos fiándonos no tanto de los expertos, sino en la autenticidad de los sistemas y procedimientos utilizados para su calibración y control, aunque no los conozcamos. Ambos, los sistemas expertos y las señales simbólicas, son tipos de desanclaje que no solo permiten remover las relaciones sociales de la inmediatez de sus contextos (Giddens, 2008: 38); además, permite comprender hasta qué punto la fiabilidad en sistemas abstractos, especialmente la fiabilidad en sistemas expertos, garantiza la reproducción y permanencia de las instituciones (Giddens, 2008: 84).

Para entender mejor el término, Giddens propone relacionar fiabilidad con cierta capacidad de presuponer un riesgo, a diferencia de la "confianza" que no lo presupone, pero que descansa en la mejor de las expectativas posibles. Quien se fía asume la responsabilidad del riesgo, quien confía, descarga la culpa en otros. Giddens establece que la fiabilidad es un estado permanente y la confianza, un tipo específico de fiabilidad (Giddens, 2008: 41), pero en ambos casos, el agente busca actuar y no paralizar la acción debido a lo que no sabe: el riesgo futuro, siempre incierto, nunca podrá paralizar la acción ni el pensamiento. Esta, la sustitución de la visión del riesgo por la de fiabilidad, es la clave del dinamismo epistémico de la modernidad. 
Finalmente, propone, entre otros, los siguientes presupuestos de la fiabilidad relacionados con la cognición y tomados de Luhmann (1988 en Giddens, 2008: 42ss.):11

1. La fiabilidad se relaciona con la ausencia en el tiempo y el espacio. Lo explícito no requiere confianza. La primera condición de la fiabilidad no es la carencia de poder sino la ignorancia.

2. La fiabilidad está ligada a la contingencia antes que al riesgo inherente de las decisiones tomadas. Si algo falla sucederá contingentemente y no cuestionará para nada las decisiones tomadas pues ellas se enmarcan en sistemas a los que atribuimos indefectibilidad, representados por personas que actúan con probidad.

3. La fiabilidad se asume como derivado de la fe y no el resultado de un conocimiento inductivo débil. Por ello, toda fiabilidad es ciega.

4. Los sistemas expertos y las señales simbólicas son fiables en orden a principios que ignoramos, y no refieren a la rectitud moral de otros. La actuación de las personas no mellan el funcionamiento de los sistemas y señales.

5. La fiabilidad se basa en la noción de riesgo, el cual a su vez supone el peligro, no necesariamente el conocimiento del peligro. La fiabilidad implica actuar sin plena conciencia del peligro.

6. La fiabilidad se maneja en espacios institucionalizados tendientes a minimizar el riesgo de dos maneras: por la habilidad y el azar (ejemplo: la bolsa financiera), y el conocimiento inductivo débil que procede por cálculo de índices de riesgo.

11 Giddens, a partir de Freud, relaciona la conciencia del riesgo (1996: 52ss.) con la "angustia", un estado general, un miedo sin objeto, y con el "temor" que sí tiene objeto. La angustia es un rasgo emotivo de la modernidad que expresa la sensación de peligro sobre los sistemas que deberían asegurar la vida en su integridad y globalidad. La angustia no permite objetivar ni delimitar sus causas y tiene que ver con la necesidad de sentir y experimentar seguridad ontológica. Luhmann (1996: 149) distingue entre "riesgo" y "peligro". Las sociedades no diferenciadas viven en la temporalidad del peligro, actual y presente, cuya amenaza se origina en una instancia externa; las sociedades modernas son sociedades del riesgo a futuro causado por las propias decisiones. La sociedad moderna percibe el peligro como riesgo. Además, Luhmann (1996: 123ss.) relaciona el riesgo con la "incertidumbre", una distinción propia de la ciencia económica, clave en la toma de decisiones empresariales, que apunta a la absorción de la incertidumbre. Alerta que la vida cotidiana nos revela marcos de conducta respecto al riesgo que desmienten estos otros marcos de la disciplina científica donde el cálculo del riesgo se encierra en juegos estadísticos. 
7. La fiabilidad distingue ambientes de riesgo que deben ser controlados mediante mecanismos de seguridad llamados a minimizar los peligros, pero no a evitar los riesgos.

Este rasgo de la modernidad (la conciencia del riesgo) inaugura la noción de un futuro siempre abierto a la contingencia y la reflexividad, pues el conocimiento experto no solo proporciona las bases para el cálculo riesgo-beneficio, sino que también crea "el universo de acontecimientos como resultado de la continua aplicación reflexiva de ese mismo conocimiento" (Giddens, 2008: 94). En definitiva, la modernidad considera los sistemas expertos como inexcusables y necesarios; al mismo tiempo que se apoyan en la estrategia de esconder entre bambalinas las inconsistencias de su propio funcionamiento (Giddens, 2008: 87), proporcionan una relativa seguridad para enfrentar la vida cotidiana a pesar de que "se trata de un medio que aspira a estabilizar los resultados, un modo de colonizar el futuro" (Giddens, 1996: 66).

Así, la lógica institucional de la modernidad concierne a las relaciones con lo viviente porque vuelve epistémica y políticamente problemática y huidiza la noción de control más allá de los sistemas expertos al mismo tiempo que imposibilita y deslegitima la construcción de capacidades mejor distribuidas socialmente para anticipar y evitar el riesgo; finalmente, los sistemas abstractos nos hacen vulnerables también porque nos hacen más interdependientes a la vez que despoja al individuo de la capacidad de actuar en otro punto del sistema (Giddens, 1996: 36).

De cierta manera, la lógica de autorreproducción de la modernidad es incompatible con la noción de control e intervención de la sociedad en la evaluación y toma de decisiones sobre los riesgos porque de alguna manera, ello equivale a que la modernidad se confronte consigo misma y tome nota de sus propias inconsistencias. La negación del riesgo implícito en la fiabilidad comporta, para la modernidad, aquel otro riesgo de confrontarse y admitir la posibilidad de su propia disolución.

Los presupuestos de la fiabilidad, que permean actitudes respecto a lo viviente, permiten comprender mejor ciertos rasgos inherentes a la práctica y ejercicio de la ciencia y el conocimiento, por ejemplo, el que la educación en la ciencia, antes que trasmitir contenidos y formas de pensar orientadas a prevenir los riesgos sobre la vida, apunte más bien a reforzar la fiabilidad en la ciencia 
y en la técnica; o que las actitudes de escepticismo y reserva se comprendan mejor como expresiones de un pacto con la modernidad que como resultado de una fiabilidad profunda, porque se requiere de esa fiabilidad para sobrellevar la vida cotidiana; y que los puntos de acceso, aquellos que conectan a los ciudadanos con los sistemas de expertos, sean lugares vulnerables e inestables pues los sistemas abstractos no pueden contener la experiencia de la gente ni hacer frente a su propia inconsistencia.

\section{Alcances, límites y enlaces con el pensamiento decolonial}

Los tres autores comparten el mismo pesimismo respecto al futuro de la vida en el planeta amenazada por los dispositivos cognitivos de la cultura técnica y de la misma modernidad. Jonas y Beck desarrollan su analítica y crítica del riesgo desde la fragilidad de la vida; en tanto que Giddens, desde los sistemas que garantizan la reproducción y expansión de las institucionalidades modernas basadas en la fiabilidad, cuyos supuestos epistémicos alimentan la misma maquinaria que entorpece la anticipación de los riesgos e impide tomar en cuenta la experiencia de la gente por sobre y más allá de los sistemas de expertos.

Los autores contribuyen a desnudar los mecanismos de negación y deslegitimación del no-saber a cuento de que el potencial de la acción humana no puede ser limitado por la incertidumbre. Tales mecanismos otorgan a los sistemas expertos de toma de decisiones de un impulso insostenible e indetenible que amenaza la vida e incrementa el riesgo, vez por vez. El aporte de Jonas, además, constata hasta qué punto se despoja de valor epistémico y político a esta imposibilidad de saber y se la ignora como derecho y condición que acompaña la existencia. Por lo tanto, este es un lugar que muestra cómo la colonialidad del saber (un patrón epistémico) se enhebra con la colonialidad respecto a la naturaleza y lo viviente y, por supuesto, con la colonialidad del poder.

A la par de estos alcances verificamos algunos límites, el primero de los cuales consiste en enfocar la crítica en las formas de conocimiento en mayor medida vinculadas con la técnica. En efecto, tanto la ciencia como las aplicaciones técnicas comparten el mismo patrón epistémico, un punto que no queda del todo claro en los autores revisados. Jonas, por ejemplo, no logra expandir 
la amplitud de su crítica a la totalidad del conocimiento e, inexplicablemente, admite que es posible paliar las consecuencias de la cultura técnica sobre la trama de la vida mediante un adecuado y mejor acompañamiento de la ciencia o de las humanidades, como si estas últimas no estuvieran atravesadas por los mismos patrones. ${ }^{12}$

El segundo límite se relaciona con la geopolítica del conocimiento pues, aunque los tres parten de una crítica a la modernidad industrial (la segunda modernidad) que hace del riesgo global su nota distintiva, no toman en cuenta del todo las dinámicas del sistema-mundo condicionadas, finalmente, por las formas de producción y acumulación del capitalismo globalizado. No se trata solo de identificar más y mejores métodos tecnológicos y sistemas apropiados de toma de decisiones globales, de gobernanza ambiental o gestión del riesgo, sino van aparejados con una analítica del sistema-mundo que hegemoniza los modos de producción así como los de pensamiento. A pesar de que la colonialidad del saber y la colonialidad de la naturaleza se enhebran en este punto de la historia de manera muy específica y puntual con la colonialidad del poder, esta trama no logra ser reconocida como constituyente de una modernidad que es también modernidad colonialidad.

Para los autores, si bien, la conciencia del riesgo plantea la posibilidad de disolución de la modernidad también propicia un punto de ruptura inmejorable para mirarse a sí misma y reconstituirse desde un horizonte más allá de la ilustración pero no más allá de la modernidad a la par que genera una expectativa de transformación que incluye la recuperación del núcleo auténtico de la modernidad, reificándola como el único marco de comprensión dotado de posibilidades para enfrentar el riesgo. Al respecto, la propuesta cosmopolita de Beck es elocuente pues mira la experiencia del riesgo global como oportunidad para superar "viejas teorías" y "viejos errores" a fin de que "el mundo nuevo que nace detrás de los viejos conceptos debe ser descubierto, el libreto de la modernidad debe reescribirse, reinterpretarse y redescubrirse" (Beck, 1999: 172).

12 Al final de su obra Técnica, medicina y ética. La práctica del principio de responsabilidad (1997), Jonas plantea una y otra vez la posibilidad de que la ciencia se constituya en el lado reflexivo de la técnica y se vuelva su fuente de control. 
El tercer límite consiste en el énfasis que otorgan a la noción necesaria pero insuficiente de "control" de la ciencia, la técnica y de las instituciones. Enfatizar el ámbito del control equivale a reconocer, por último, la legitimidad de los dispositivos de conocimiento de la cultura técnica, a pesar de estar armados para poner en riesgo la trama de la vida y garantizar la voluntad de autoafirmación de los humanos sobre aquello que objetivan (el futuro, la naturaleza y los otros). Por tanto, no deben ser solo controlados o desactivados circunstancialmente, sino también removidos. La noción de control, a su vez, se ubica en la antesala de la noción de cuidado de lo viviente a la que Jonas le presta mucha atención y que se ha desarrollado y enriquecido luego con la tradición de pensamiento del movimiento feminista y ecologista. ${ }^{13}$

Para culminar, las implicaciones epistémicas del riesgo plantean la siguiente interrogante: ¿cuáles son los enlaces de estos aportes con el pensamiento decolonial y de qué miradas interculturales requieren para proyectarse a sí mismos más allá de sus límites? Esbozamos dos posibles enlaces que abren horizontes a futuras búsquedas. El primero consiste en que la imposibilidad de saber, en tanto derecho y condición existencial, se enlaza con algunos aportes del pensamiento indígena para los cuales el saber resulta una condición inestable y precaria, susceptible de ser perdida o restaurada vez por vez (véase Lenkesdorf, 2005: 23ss.). Para el pensamiento afrocaribeño, además, el no-saber constituye, ante todo, un estigma desacreditante y autoincriminante propio de la epistemología colonial disciplinaria, que induce a la negación compulsiva de esta condición existencial. Ambos derroteros del pensamiento decolonial - el indígena y el afrocaribeño - sugieren que el reconocimiento del no-saber como condición existencial pudiera iluminar de otra manera el ejercicio de la toma de decisiones compartidas sobre la vida, porque ambas instancias, la vida y el pensamiento, se mueven en el mismo circuito de precariedad e incertidumbre. ${ }^{14}$

13 El movimiento feminista ha cultivado, a su manera, la noción de "cuidado", por ejemplo, Carol Gilligan (La moral y la teoría. Psicología del desarrollo femenino, 1986, véase también el análisis de Ana Fascioli [2010]).

14 En este aspecto es fundamental el aporte del filósofo afrocaribeño Lewis Gordon: "la ironía de nuestra época es que, mientras hay una obsesión por parecer inteligentes, pensar se ha convertido en una actividad indecente. Quizás el indicador más evidente de la declinación del pensamiento es el fenómeno de nunca parecer equivocado [...]. No importa cuán grande sea la evidencia en su contra [...], la negación del error conlleva a la ausencia de falta" (Gordon, 2013: 19). 
El segundo enlace lo provoca la noción de "cuidado" alimentada por Jonas que supone, empero, un sujeto que subalterniza lo otro en cuanto "objeto de cuidado". Pensamos que esta noción solicita ser prolongada en la actitud de "crianza" que, en cambio, abriga la posibilidad de concebir la vida como totalidad que nos envuelve en un circuito de compromisos mutuos y compartidos. No es lo mismo una epistemología que favorezca el control y el cuidado que aquella que haga posible la crianza de la vida. ${ }^{15}$

Estos enlaces otorgan perspectiva a las implicaciones epistémicas del riesgo tal como la concisen los autores revisados y plantean la necesidad de acudir a otros marcos civilizatorios, a un horizonte decolonial intercultural más allá de la modernidad eurocéntrica. Sugieren la posibilidad de mirar y reconocer otros marcos de pensamientos y prácticas que harían posible superar el encierro de la modernidad en sí misma que se las arreglará, siempre, de lidiar con la vida para comprenderla o modificarla, pero nunca para hacerse cargo de ella.

\section{Bibliografía}

Beck, U.

1996 “Teoría de la sociedad del riesgo" y "Teoría de la modernización reflexiva”. En: Beriain, J. (comp.), Las consecuencias perversas de la modernidad. Modernidad, contingencia y riesgo. Barcelona: Anthropos, pp. 201-266.

Beck, U.

1998 La sociedad del riesgo: Hacia una nueva modernidad. Barcelona: Paidós.

Beck, U.

1999 "La teoría de la sociedad del riesgo reformulada". En: Revista Chilena de Temas Sociológicos. Año 3. № 4-5, pp. 11-42.

Beck, U.

2008 La sociedad del riesgo mundial. En busca de la seguridad perdida. Barcelona: Paidós.

Beriain, J. (comp.)

15 El pensamiento indígena andino ha introducido la noción de "crianza de la vida”, por ejemplo, Luis Enrique Cachihuango y Julián Pontón (2010), que describen aspectos relacionados con la crianza del agua. 
1996 Las consecuencias perversas de la modernidad. Modernidad, contingencia y riesgo. Barcelona: Anthropos.

Cachiguango, L. E. y Pontón, J.

2010 Yaku Mama: La crianza del agua. Otavalo: Ministerio de Cultura del Ecuador.

Fascioli, A.

2010 "Ética del cuidado y ética de la justicia en la teoría moral de Carol Gilligan". En: Revista Actio. N $^{\circ}$ 14. Departamento de Filosofía de la Práctica-UDELAR.

Gordon, L.

2013 Decadencia disciplinaria. Pensamiento vivo en tiempos dificiles. Quito: Abya-Yala.

Escobar, A.

2003 "Mundos y conocimientos de otro modo. El programa de modernidad/colonialidad latinoamericano”. En: Tabula Rasa. 1:51-86. Bogotá.

Giddens, A.

1996 "Modernidad y autoidentidad”. En: Beriain, J. (comp.), Las consecuencias perversas de la modernidad. Modernidad, contingencia y riesgo. Barcelona: Anthropos, pp. 33-72.

Giddens, A.

2007 Europa en la era global. Barcelona: Paidós.

Giddens, A.

2008 Consecuencias de la modernidad. Madrid: Alianza.

Horkheimer, M.

2003 Teoría crítica. Buenos Aires: Amorrortu.

Jonas, $\mathrm{H}$.

1984 The Imperative of Responsibility. In Search of an Ethics for the TechnologiJonas, $\mathrm{H}$. cal Age. Chicago-London: The University of Chicago Press.

1995 El principio de responsabilidad. Ensayo de una ética para la civilización tecnológica. Barcelona: Herder.

Jonas, $\mathrm{H}$.

1997 Técnica, medicina y ética. La práctica del principio de responsabilidad. Barcelona: Paidós.

Jonas, $\mathrm{H}$.

2000 El principio vida. Barcelona: Trotta.

Jonas, $\mathrm{H}$. 
2005 Poder e impotencia de la subjetividad. Barcelona: Paidós.

Lander, E.

1994 La ciencia y la tecnología como asuntos políticos. Límites de la democracia en la sociedad tecnológica. Caracas: Universidad Central de Venezuela.

Lander, E.

2000 "Ciencias sociales: saberes eurocéntricos y coloniales". En: Lander, E. (comp.), La colonialidad del saber. Eurocentrismo y ciencias sociales. Perspectivas latinoamericanas. Buenos Aires: UNESCO/CLACSO.

Lander, E. (comp.)

2000 La colonialidad del saber. Eurocentrismo y ciencias sociales. Perspectivas latinoamericanas. Buenos Aires: UNESCO/CLACSO.

Lander, E.

2009a "Los límites del planeta y la crisis civilizatoria. Ámbitos y sujetos de las resistencias". Fotocopiado. Buenos Aires.

Lander, E.

2009b “Tendencias dominantes de nuestra época. ¿Se nos agota el tiempo?”. En: Compendium. Vol. 12. No 22, julio de 2009, pp. 81-106.

Lander, E.

2010 "Crisis civilizatoria: el tiempo se agota". En: León, I. (coord.), Sumak Kawsay/Buen Vivir y cambios civilizatorios. Quito: FEDAEPS.

Lenkesdorf, C.

2005 Los hombres verdaderos. Voces y testimonios tojolabales. México: Siglo XXI.

Luhmann, N.

1996 "El concepto de riesgo", "El futuro como riesgo" y "La contingencia como atributo de la sociedad". En: Beriain, J. (comp.), Las consecuencias perversas de la modernidad. Modernidad, contingencia y riesgo. Barcelona: Anthropos, pp. 123-198.

Envío 25 de octubre/2013 - Aceptación 17 de diciembre/2013 